\title{
Longitudinal population-based studies of affective disorders: Where to from here?
}

\author{
John R Beard ${ }^{1,2,3}$, Sandro Galea*1,4,5 and David Vlahov ${ }^{1,6}$
}

Address: ${ }^{1}$ New York Academy of Medicine, New York, New York, USA, ${ }^{2}$ School of Public Health, University of Sydney, Sydney, Australia, ${ }^{3}$ Faculty of Health and Applied Sciences, Southern Cross University, Lismore, Australia, ${ }^{4}$ Department of Epidemiology, University of Michigan School of Public Health, Ann Arbor, MI, USA, ${ }^{5}$ Department of Epidemiology, Columbia University Mailman School of Public Health, New York, NY, USA and ${ }^{6}$ Department of Epidemiology, Johns Hopkins Bloomberg School of Public Health, Baltimore, MD, USA

Email: John R Beard - jbeard@nyam.org; Sandro Galea* - sgalea@umich.edu; David Vlahov - dvlahov@nyam.org

* Corresponding author

Published: 23 September 2008

BMC Psychiatry 2008, 8:83 doi:10.1 186/1471-244X-8-83

This article is available from: http://www.biomedcentral.com/I47I-244X/8/83

(c) 2008 Beard et al; licensee BioMed Central Ltd.

This is an Open Access article distributed under the terms of the Creative Commons Attribution License (http://creativecommons.org/licenses/by/2.0), which permits unrestricted use, distribution, and reproduction in any medium, provided the original work is properly cited.
Received: 9 May 2008

Accepted: 23 September 2008

\begin{abstract}
Background: Longitudinal, population-based, research is important if we are to better characterize the lifetime patterns and determinants of affective disorders. While studies of this type are becoming increasingly prevalent, there has been little discussion about the limitations of the methods commonly used.
\end{abstract}

Methods: Discussion paper including a brief review of key prospective population-based studies as the basis for a critical appraisal of current approaches.

Results: We identified a number of common methodological weaknesses that restrict the potential of longitudinal research to characterize the diversity, prognosis, and determinants of affective disorders over time. Most studies using comprehensive diagnostic instruments have either been of relatively brief duration, or have suffered from long periods between waves. Most etiologic research has focused on first onset diagnoses, although these may be relatively uncommon after early adulthood and the burden of mental disorders falls more heavily on individuals with recurring disorders. Analysis has tended to be based on changes in diagnostic status rather than anges in symptom levels, limiting study power. Diagnoses have generally been treated as homogeneous entities and few studies have explored whether diagnostic subtypes such as atypical depression vary in their etiology or prognosis. Little research has considered whether there are distinct trajectories of symptoms over time and most has focused on individual disorders such as depression, rather than considering the relationship over time between symptoms of different affective disorders. There has also been limited longitudinal research on factors in the physical or social environment that may influence the onset, recurrence or chronicity of symptoms.

Conclusion: Many important, and in some respects quite basic, questions remain about the trajectory of depression and anxiety disorders over the life course and the factors that influence their incidence, recurrence and prognosis. Innovative approaches that consider symptoms of all affective disorders, and how these change over time, has the potential to greatly increase our understanding of the heterogeneity of these important conditions and of the individual and environmental characteristics that influence their life course.

Using longitudinal research to define sub classes of affective disorders may also be of great benefit for studies seeking to define the genetic determinants of susceptibility to these conditions. 


\section{Background}

Mental disorders are among the conditions causing the greatest burden on human health, with estimates in developed countries of the 12 month prevalence of depression alone ranging between $3.1 \%$ and $10.3 \%$ percent of the general population. [1,2] However, despite the demonstrated effectiveness of a range of interventions, many individuals with mental disorders will never seek clinical help $[3,4]$. This highlights the need for population based epidemiologic research, since study populations drawn only from clinical settings may not be representative of the broader community.

Recent large population based surveys have improved our understanding of the high prevalence and significant consequences of mental disorders. [1,2,5-8] These studies have identified a range of socio-demographic factors, behaviors, and traits that may be associated with the presence of common disorders including life stressors, female gender, past or family history[9], and personality traits (in particular neuroticism, self esteem and self criticism). $[10,11]$ Some of these surveys have also attempted to establish a picture of the life course of these disorders by inquiring about the lifetime history of symptoms. [12]

However, retrospective approaches are limited in their ability to portray lifetime patterns of anxiety and depressive disorders since they are dependent on participant recall of past symptoms. This may be limited, particularly for nonpsychotic disorders. [13] Longitudinal, research is better placed to characterize the course of these disorders and to investigate the determinants of incidence, recurrence and prognosis. An increasing number of prospective studies are being undertaken to explore these issues, although the methods applied to this research are in their infancy and there has been little debate on the approaches that are widely used. The goal of this paper is to examine the methods commonly taken by longitudinal, population-based, psychiatric epidemiologic studies, to explore the conceptual and methodological issues arising from these studies, and to discuss the implications of these issues for future research designs.

\section{Methods}

Much longitudinal research in this field has relied on brief "screening" measures focused on a single affective disorder such as depression. It would be impossible for any one paper to adequately describe the diversity of approaches taken in this body of research, let alone critique the study methods. A more limited number of population based studies have used comprehensive diagnostic measures which can identify a range of mental disorders. These more complex instruments allow examination of comorbidity and movement from one diagnostic category to another. Since a better understanding of these issues is vital for future research, and since the methodological issues that arise from research using complex instruments are relevant to all longitudinal studies in mental health, we undertook a review of longitudinal studies of mental disorders using structured diagnostic instruments. We use examples from this pool of research to highlight methodological and conceptual challenges that confront all researchers using longitudinal approaches in this field.

\section{Search strategy}

We searched MEDLINE for articles including the key words "depression" or "anxiety disorders" in the following key word subheadings: diagnosis, epidemiology, ethnology, etiology, genetics and prevention \& control. We also included all articles with the words "depression", "anxiety disorders" or "mental disorders" in the title or abstract. We limited our search to studies on humans and published in English language journals between 1990 and January 2007. 119,939 articles were identified. We further limited our review to the 14610 studies that either included the words "longitudinal", "cohort" or "prospective" in the abstract or title, or included "longitudinal studies", "cohort studies" or "prospective studies" as key words. We then restricted these to studies using structured diagnostic instruments and thus including either "Diagnostic Interview Schedule", "Composite International Diagnostic Interview" or "Clinical Interview Schedule" in the title or abstract. A total of 287 publications were found meeting these criteria. We identified all studies in adults (but including studies starting in earlier life) that had an initial cohort of over 1000 subjects drawn from the general population at first interview, with a minimum of one further interview. Studies needed to use a structured diagnostic instrument for the whole sample in at least two waves, and samples drawn from primary care or outpatients clinics were excluded. A summary of the key studies identified is shown in Table 1 . We have not attempted to summarize the wealth of findings this body of research has generated, except where it is relevant to our discussion of methods. We particularly focus on incidence estimates, as this allows us to later explore key methodological issues. Where a study resulted in multiple outputs, we have only cited those most relevant to the point being raised.

\section{Results}

The United States Epidemiological Catchment Area (ECA) Program remains a benchmark in this field. The study involved five sites, with a total sample size of over 15,000 participants 18 years or older. Participants were first interviewed in 1981, followed by a second interview after 6 months at one site, and a 6 month telephone interview followed by a repeat mental health interview at one year for other sites. $[14,15]$ Follow-up rates ranged from 78 to $83 \%$. The Baltimore arm of the ECA study undertook fur- 
Table I: Key longitudinal studies discussed

\begin{tabular}{|c|c|c|c|c|c|c|c|}
\hline Study & Country & Years & Instrument & $\begin{array}{l}\text { Follow-up } \\
\text { rate }\end{array}$ & Waves & $\begin{array}{l}\text { Baseline Age } \\
\text { Range }\end{array}$ & $\begin{array}{l}\text { Initial cohort } \\
\text { size }\end{array}$ \\
\hline $\begin{array}{l}\text { Dunedin Multidisciplinary Health } \\
\text { and Development Study } \\
\text { (DMHDS) (Krueger et al., 1998) }\end{array}$ & New Zealand & $1972-$ & Modified DIS & $92.7 \%$ & 10 & Birth cohort & 1037 \\
\hline $\begin{array}{l}\text { Christchurch Health and } \\
\text { Development Study } \\
\text { (Fergusson and Horwood, 200I) }\end{array}$ & New Zealand & 1977 - & $\begin{array}{l}\text { Modified DIS for } \\
\text { Children; CIDI } \\
\text { component }\end{array}$ & $80 \%$ & 21 & Birth cohort & 1265 \\
\hline $\begin{array}{l}\text { Epidemiologic Catchment Study } \\
\text { (ECA) (Eaton et al., 1984) }\end{array}$ & USA & $1981-1982$ & DIS & $78-83 \%$ & 2 & 18 years and older & $10,86 \mid \quad 10,185$ \\
\hline $\begin{array}{l}\text { Baltimore ECA } \\
\text { (Chen et al., 2000) }\end{array}$ & USA & $1981-1994$ & DIS & $73 \%$ & 3 & $\begin{array}{l}\text { I8 years and older (small } \\
\text { oversampling of elderly) }\end{array}$ & 3481 \\
\hline New Haven ECA & USA & $1980-1982$ & DIS or CESD & $81 \%$ & 2 & $\begin{array}{l}\text { I8 years and older (large } \\
\text { oversampling of elderly) }\end{array}$ & $\begin{array}{c}5034 \\
\text { (1977 elderly) }\end{array}$ \\
\hline $\begin{array}{l}\text { National Comorbidity Study - } 2 \\
\text { (Kessler, Merikangas et al., } \\
\text { 2003b) }\end{array}$ & US & 1990-2002 & CIDI & $76.6 \%$ & 2 & $15-54$ years & 8098 \\
\hline $\begin{array}{l}\text { Michigan Community Sample } \\
\text { (Breslau et al., 2005) }\end{array}$ & US & $|989-200|$ & DIS & $89 \%$ & 4 & $21-30$ years & 1007 \\
\hline $\begin{array}{l}\text { Early Developmental Stages of } \\
\text { Psychopathology } \\
\text { (EDSP) (Stein et al., 200I) }\end{array}$ & Germany & 1994-2004 & Munich CIDI & $84 \%$ & $\begin{array}{c}2 \text { (plus } 10 \text { year } \\
\text { follow-up of partial } \\
\text { wave) }\end{array}$ & $14-24$ years & 3021 \\
\hline $\begin{array}{l}\text { Northern Rivers Mental Health } \\
\text { Study } \\
\text { (NoRMHS) (Beard et al., 2006) }\end{array}$ & Australia & $1996-1998$ & CIDI & $69 \%$ & $\begin{array}{c}2 \\
\text { (plus screening) }\end{array}$ & 18 years and older & 1407 \\
\hline $\begin{array}{l}\text { Netherlands Mental Health } \\
\text { Survey and Incidence Study } \\
\text { (NEMESIS) (De Graaf et al., } \\
\text { 2002) }\end{array}$ & Nether-lands & 1996-1999 & CIDI & $65 \%$ & 3 & $18-64$ years & 7076 \\
\hline $\begin{array}{l}\text { British National Household } \\
\text { Survey (Brugha et al., 2005) } \\
\text { (Skapinakis et al., 2006) }\end{array}$ & UK & 2000-2002 & CIS-R & $68 \%$ & 3 & $16-74$ years & $\begin{array}{c}3536 \text { (stratified } \\
\text { sample of first wave) }\end{array}$ \\
\hline $\begin{array}{l}\text { Aldona prospective study } \\
\text { (Patel et al., 2006) }\end{array}$ & India & $200 I-2003$ & CIS-R & $87 \%$ & 3 & $18-50$ years & 2494 women \\
\hline
\end{tabular}

ther reinterviews between 1993 and 1996, with 73\% follow-up of survivors.

The initial follow-up found 12 month first incidence (i.e. excluding participants with previous history) of disorders ranging from 1.59 per 100 person years for depression to 3.98 per 100 person years for phobic disorders. [16] However, when participants were followed up for longer periods in the Baltimore ECA, incidence rates dropped markedly with the annual incidence of first depression falling to 3.0 per 1000 person years. Severe depression was associated with female gender and family history, but not stressful life events, while mild and moderate depression was associated with family history and stressful life events, but not female gender. $[17,18]$

More recently, the Netherlands Mental Health Survey and Incidence Study (NEMESIS) followed randomly selected participants aged from 18-64 years from the Dutch adult population with assessments in 1996, 1997 and 1999. [18] 7076 participants were recruited to the first wave (69.7\% of eligible persons), with 4796 followed over all three waves. In multivariate analysis, NEMESIS found that a high neuroticism score, female gender and negative life events or ongoing difficulties increased the chance of a participant developing depression, as did sleep problems at baseline. For anxiety, female gender, negative life events or ongoing difficulties and baseline symptoms or pres- ence of a mood disorder were all significant predictors. For participants with depression at baseline, predictors of persistence included severity and low social support. [19] NEMESIS estimated the first incidence of DSM-III-R disorders at 5.6 (95 percent confidence interval:4.8-6.4) per 100 person years, with an incidence for depression of 3.1 per 100 person years (95\% CI: 2.6-3.6). [20]

In Germany, the Early Developmental Stages of Psychopathology Study recruited 3021 participants 14-24 years of age in 1995 (response rate 71\%). A sample of younger participants was initially reassessed, and then reinterviews were attempted with all participants 42 months after baseline (2548 participants reinterviewed - follow-up rate $84 \%)$. A 10 year follow-up has recently been completed. [21] The investigators used the Munich CIDI to explore outcomes including suicidality, the course of post traumatic stress disorder, the influence of cannabis use on psychotic symptoms, the role of trauma and PTSD on premenstrual disorders, and the predictive significance of anxiety disorders on first onset of major depression. [2226]

In the US, the National Co-morbidity Study (NCS) of 8098 participants aged 15-54 years reinterviewed 4375 participants (follow-up rate $76.6 \%$ ) approximately 10 years after their initial interview and papers from this cohort are just starting to become available. [27] In the 
UK, a stratified sample of the original 8000 respondents to the 2000 Psychiatric Morbidity Survey (all of those with a definite or sub-threshold psychiatric disorder and a $20 \%$ random sample of those without such disorder) were contacted eighteen months later for a follow-up interview. 2413 of 3536 were successfully re-interviewed $(68 \%$ response rate). [28] This cohort has been used to explore a range of possible social determinants of mental health.

Other longitudinal studies have focused on specific population subsections including a cohort of 120021 to 30 year old members of a large health maintenance organization in southeast Michigan followed over 4 waves (899 participants interviewed in all waves)[29], and a three wave study of 2494 women aged 18-50 years in India. [30]

One weakness of these large studies is that they have difficulty accurately determining either prior history, the sequence in which these disorders may develop, or the influence on their development of a range of childhood experiences. To do this, detailed information going back to early childhood is required. Two cohorts in New Zealand have been followed over extended periods from birth to early adult life, allowing investigation of these issues.

The Christchurch Health and Development Study (CHDS) is a longitudinal study of a birth cohort of 1265 children born in the Christchurch urban region during mid 1977. [31] Participants have been studied at repeated (until age 16, annual) intervals across their life course, including detailed assessment of mental health outcomes using the DIS and, later, the CIDI. Loss to follow-up over this period has been limited to approximately $20 \%$. This study has been able to investigate a number of crucial issues in mental health. For example, it has suggested that the influence of childhood experiences such as divorce or separation on later mental health is less important than the influence of events leading up to separation, that a predominantly homosexual sexual orientation may be associated with greater risk of depression[32], and that the risk of suicidal behavior depends on accumulative exposure to adverse childhood circumstances, personality factors, mental disorders and exposure to adverse life events.

The Dunedin Multidisciplinary Health and Development Study is a similar birth cohort study conducted in New Zealand, following 1037 participants with regular assessments to age 26, and using the Diagnostic Interview Schedule for assessment of mental health status. [33] Loss to follow-up at age 21 was limited to an extraordinary $7.3 \%$. Among many other findings, this study suggested a close link between personality traits and the later development of mental disorders [34] and, more recently, identified an interaction of the serotonin transporter (5-HTT) gene on the influence of life stressors on incident depression. [35]

While studies using brief instruments are too numerous to detail in this paper, their findings are generally consistent with those of the studies outlined above that have used more comprehensive structured interviews, although their estimates of incidence and prevalence have tended to be higher. [36] They include an extensive research program in twins that has proposed comprehensive developmental models for depression that explain approximately half of the variance in the liability to depressive episodes. $[37,38]$

\section{Key questions that could be answered by longitudinal studies}

While this extensive body of research is fundamental to our current understanding of mental health, fundamental questions remain (Table 2 ).

\section{Disorders across the life course}

We still have only a limited understanding of the natural course of these disorders across a lifetime. The birth cohort studies have shed considerable light on the evolu-

Table 2: Some important questions that can be answered by longitudinal research

\begin{tabular}{|c|c|}
\hline \multicolumn{2}{|c|}{ Characterization of affective disorders } \\
\hline \multirow[t]{5}{*}{ Symptoms across the life course } & What is the lifetime prevalence of disorders? \\
\hline & Do disorders tend to appear in a particular order? \\
\hline & Is there a prodrome? \\
\hline & Are there distinct trajectory subtypes and do these have the same aetiology? \\
\hline & Are there distinct subtypes of symptom patterns over time? \\
\hline Classification of disorder & $\begin{array}{l}\text { Are current classifications adequate or are there higher order structures that better represent affective } \\
\text { disorders and their evolution over time? }\end{array}$ \\
\hline \multicolumn{2}{|l|}{ Aetiology of affective disorders } \\
\hline Determinants of recurrence & $\begin{array}{l}\text { Are the factors that influence disorder recurrence or transformation to new disorder/comorbidity the } \\
\text { same as those that determine incident symptoms? }\end{array}$ \\
\hline Influence of environmental factors & Does an individual's physical and social environment influence changes in symptom levels or type? \\
\hline Genetic research & Do specific syndrome or trajectory subtypes have distinct genetic determinants? \\
\hline Heterogeneity & Do specific syndrome or trajectory subtypes have differing etiology? \\
\hline
\end{tabular}


tion of mental disorders in childhood adolescence and early adulthood, but these are small cohorts and patterns beyond early adulthood are less clear. The Baltimore ECA suggests a secondary peak in incidence of depression around the mid 50's. [39] If this could be confirmed, it would be useful to understand why this occurs and whether it can be prevented. It is also unclear what happens to the prevalence of mental disorders in older age. Studies using brief instruments suggest higher rates of depression, but this may be due to higher sensitivity of the measures used. [40] The limited longitudinal research that has followed participants into older age suggests a slight increase in prevalence, but this may simply be a response to increasing disability. $[41,42]$

\section{Classification of disorders}

There has been longstanding debate on whether current diagnostic categories of affective disorders accurately reflect the complexity of these conditions. Many individuals suffer comorbidity from more than one mental disorder and many individuals with a "pure" disorder without comorbidity later develop other disorders. These patterns are a challenge for longitudinal research, but prospective studies also provide an ideal vehicle to further our understanding of these issues and to help resolve debate as to the nosology and etiology of these conditions. [43]

At least two perspectives have been suggested, with some researchers tending to favor the existing categorical approach, and others looking to higher order structures in a search for common etiologic and pathologic processes. Factor analysis of the National Comorbidity Survey has been used to promote the latter approach, suggesting an alternative model in which disorders are divided into those representing externalizing or internalizing problems with the latter having two sub factors - anxious-misery and fear. [44] These findings are supported by two prospective studies. [45,46] However, a large prospective study of adolescents found that anxiety disorders generally preceded the onset of depression, and that the risk factors for both were distinct. [47] A recent analysis of the Christchurch cohort examined changing symptoms over three waves and found that both perspectives may be valid: participants appeared to have symptoms correlated across the study period that were consistent with broad generalized internalizing, but there was also evidence of across-time continuity in disorder-specific components of symptoms. [48]

Longitudinal research can help our understanding of the nature of common mental disorders and our system of classification. However, to do this, information is needed on the full range of affective symptoms in participants at relatively frequent intervals over long follow up periods. This is currently limited by the lack of dimensional symp- tom measures for all participants in current structured instruments (see below) and the inability of studies using a single brief measure to capture comorbidity patterns.

\section{Determinants of recurrence}

Much of the focus of recent longitudinal research has been to identify the incidence and determinants of new diagnoses of mental disorders in participants without a prior history. However, such analysis has generally depended on participant recall of past symptoms. There is little evidence to confirm the accuracy of recall of lifetime symptoms, test retest studies suggest it may be surprisingly high for psychotic symptoms, but less so for nonpsychotic disorders. [13] This concern is supported by the Baltimore ECA, which found 17 of the 22 episodes of depression reported at the 1982 interview were not reported at the 14 year follow-up. [39]

The bias that is likely to result from these recall limitations is clearly demonstrated in the estimates of the onset ("incidence") of new disorders reported by different studies. Initial first incidence estimates of depression in the Baltimore ECA dropped markedly when longer follow-up allowed more objective assessment of psychiatric history. This presumably reflects participants who may have self reported no prior history but who were excluded on more objective assessment. The incidence of depression found by NEMESIS was similar to the original ECA results, reflecting reliance on self reported history, while the incidence in studies of participants with and without past history, is double this. [49]

It is important to better characterize the true incidence of first onset disorders and identify the factors associated with them. However, the Baltimore ECA findings suggest that first onset of depression after early adulthood is relatively rare. From a public health perspective, the burden of disease associated with first onset of disorders after early adulthood is far less than that posed by recurrence of these disorders (or worsening of symptoms) throughout the rest of life. Yet little research has explored the factors that influence disorder recurrence. These may, or may not, be distinct from those that influence first incidence.

In practical terms, excluding participants with prior history from analyses results in a considerable loss of information and power. From a public health standpoint, there is a clear imperative to identify modifiable factors that impact on the recurrence of disorder or exacerbation of symptoms in the high proportion of the population with a lifetime history.

\section{Heterogeneity of disorders}

Clinical experience suggests that affective disorders are heterogeneous in nature. A neglected area of longitudinal 
research is whether different symptom patterns may be associated with different etiologic pathways and prognoses. A number of studies have used latent class analysis to identify possible depression sub classes. One study of twins identified three clinically significant depressive syndromes: mild typical depression, atypical depression, and severe typical depression. [50] Individuals with recurrent episodes tended to have the same syndrome on each occasion and genetic makeup appeared to be a significant factor in this tendency. Latent Class Analysis of the National Comorbidity Survey found four slightly different clinical subtypes for depression: mild/severe and typical/atypical. [51] Importantly, the association of various risk factors differed by subtype, with atypicality being associated with interpersonal dependency and reduced self esteem. The Baltimore ECA also used Latent Class Analysis to identify depressive subtypes. [17] Severity was associated with female gender and family history but not stressful life events, while mild or moderate cases were associated with family history and stressful events, but not female gender.

These findings are significant since they suggest that differing subtypes of specific affective disorders (for example individuals with symptoms over time of both depression and generalized anxiety disorder) may vary in their susceptibility to particular risk factors. If these disorders are categorized as homogeneous entities, these relationships may be obscured in analysis. Longitudinal analysis with the power to follow different subgroups over time may be able to identify risk factors for recurrence that are specific for disorder type.

\section{Disorder trajectories}

Longitudinal research also offers the potential to examine changing patterns (trajectories) of symptoms over time. [41,52-55] The limited research in this field has generally been consistent with a trait-state model where depression symptomatology is accounted for by two factors: an underlying "trait" effect that is highly heritable and reflects underlying vulnerability, and a residual "state" effect that is less inheritable and more likely to reflect circumstances at a point in time. Distinguishing these patterns is another area that is worthy of future research since it may be more appropriate for etiologic studies to examine the influence of external factors on "state" effects rather than the more stable "trait" effects. It is also possible that some disorder subclasses (for example individuals who over time may experience both depressive and generalized anxiety disorders) may experience different vulnerabilities to particular risk factors than others (for example an individual with no such comorbidity). Distinguishing these comorbidities over time in analysis may give us a better understanding of the risk factors for these individuals.

\section{Influence of environmental factors}

Our understanding of how the physical and social environment influences the recurrence of mental disorders is also very limited. A number of neighborhood level factors, including social disorder, neighborhood safety, social connectedness and neighborhood socioeconomic status or disparity have been suggested as possible influences on the risk of an individual developing an affective disorder. [56-58] This might be because they potentially serve a role ameliorating stressful exposures, or may themselves comprise one. Longitudinal studies are particularly important in this area, since associations identified in cross-sectional research may simply reflect a tendency for people with recurring disorders to congregate in particular areas, or have similar social habits, rather than these associations being causal in nature. While the large cohort studies have considerably increased our understanding of the individual level determinants of common mental disorders, few have explored in depth the influence of neighborhood level factors. Where factors from the physical and social environment have been considered by these studies and those using brief instruments, these have generally relied on participant self report which may itself be influenced by confounding factors such as age, gender, symptom severity or personality traits. Large studies with more objective measures of these complex factors are needed to help us better understand the role of these potentially modifiable environmental determinants.

\section{Genetic research}

It is beyond this paper to examine in detail the potential arising from recent advances in our understanding of the human genome. However, association studies for mental disorders have tended to be based on cross sectional disorder categorizations and have generally considered affective disorders as homogeneous entities. [59] Yet, symptom and trajectory subtypes are likely to reflect quite distinct genetic susceptibilities. [50] Stratifying association studies by these subtypes may be a productive avenue for future research. Using longitudinal studies to identify subclasses of affective disorders is therefore likely to also advance our search for their genetic determinants.

Similarly, by allowing populations to be subtyped by genetic susceptibility, advances in genetic research may offer great potential for longitudinal research into individual and environmental risk factors. [60] Gene-environment interaction approaches that better characterize genetic influences on individual susceptibility and explore the heterogeneity in response to environmental precipitants are likely to be particularly fruitful. [59]

\section{Moving Forward}

A number of design elements need to be considered if longitudinal studies are to answer these, and other, important 
questions. As a starting point, more studies need to be conducted in large samples of the general population, with symptoms of both anxiety and depression assessed repeatedly over an extended period.

\section{Measurement of outcomes}

While some researchers have expressed concern that the validity of structured diagnostic instruments is stronger for high prevalence clinical settings[61] than in non-clinical populations $[62,63]$, there is considerable evidence that positive diagnoses in population surveys using these instruments correlate well with disability $[64,65]$.

However, in longitudinal research it is also important that changes in diagnosis identified by these instruments reflect meaningful changes in symptoms rather than minor symptom changes in participants lying just above or below diagnostic cutoffs. For example, an individual with several symptoms of depression but not meeting one of the key criteria might simply change this one response to shift from a negative to a positive diagnosis. It is conceivable that respondents who experience several waves of interviews may learn to answer no to such gateway questions as a way of shortening the interview. There has been little assessment of the strength or validity of instruments such as the World Mental Health(WMH)-CIDI to measure change. Some reassurance comes from Australian research in which over three quarters of participants developing a new diagnosis had one or no symptoms at baseline, while three quarters of those meeting all symptom criteria at baseline were depression free two years later [49]. While this may partly reflect the stem structure of the CIDI instrument, such major shifts in symptom levels seem likely to reflect clinically meaningful changes. However, there is very limited additional evidence to support this conclusion and this is an area worthy of further examination.

A related issue is the reliance of these instruments on categorical outcomes (i.e. diagnoses of depression or anxiety disorders). While this is useful for examining the natural course of mental disorders, it may be less than ideal when exploring their determinants. For example, the Christchurch study, found "evidence of continuous and generally linear dose-response functions between symptom severity and outcome risks and that dimensionally scored variables were considerably better predictors of outcome than measures based on diagnostic classification". [66] The NEMESIS study also found subthreshold expressions of depression and (hypo)mania to be continuous with more clinical states and that they strongly predicted post baseline mood disorders. [67] Limiting analysis to considering mental disorders as categorical outcomes is thus wasteful of information and weakens study power. [68]
To address this need, the WMH-CIDI now incorporates a dimensional measure of depressive symptoms, the Quick Inventory of Depressive Symptomatology - Self Report (QIDS-SR). [69] However, this is only invoked if a stem depression question is positive limiting the ability to examine symptom change in all responders over time. Another limitation of structured diagnostic instruments is their length, which in some cases may take several hours, with a high associated cost of administration. This can influence both sample size and frequency of follow-up.

Brief measures have the potential to address many of these problems in longitudinal research, and some have been surprisingly well validated. For example, in validation against structured mental health professional interviews, the Patient Health Questionnaire (PHQ), a 9 item depression measure, had a sensitivity of $88 \%$ for major depression with a specificity of $88 \%$. [70] A more recent validation of the PHQ against the Structured Clinical Interview for DSM-IV (SCID) found 90\% sensitivity and $83 \%$ specificity for diagnosis of major depressive disorder. [71] This compares favorably with the assessment of non psychiatrically trained physicians (sensitivity $40 \%$; specificity, $87 \%$ ) and with the CIDI (overall concordance with SCID of $87 \%)$. [72]

However, an issue that is of particular concern with brief instruments arises from the potential for comorbidity of mental disorders. A brief instrument for a specific outcome such as depression is not capable of distinguishing individuals who may also be suffering from a separate, possibly related, disorder such as generalized anxiety disorder. This prevents examination of the relation between these outcomes over time and also limits genuine assessment of new onsets. For example, individuals identified by a brief instrument as being depression free may, in fact, have unidentified symptoms of an anxiety disorder and a high level of psychological distress. It is debatable whether it is reasonable to consider symptoms of depression that develop in such an individual as being a true new onset of psychopathology.

One solution may be multi-outcome brief measures which could be used to categorize participants for both depression and anxiety disorders. The PHQ, for example, has an additional anxiety component. However, the complexity of anxiety disorders means these brief instruments can generally only assess symptoms of some anxiety disorders, leaving participants with other disorders (e.g. obsessive compulsive disorder) unidentified. With this approach, the limitations of categorical analysis also continue.

As with structured instruments, there are considerable advantages for brief instruments that can measure changes 
in symptom levels rather than just the presence or absence of diagnoses. A number of brief dimensional depression measures, including the PHQ and the QIDS-SR, have been shown to be sensitive to symptom change. Anxiety measures, such as the State Trait Anxiety Inventory, that are less tied to specific DSM-IV diagnoses and capture both underlying anxiety trends and those more related to immediate circumstances, may be the best option for dimensional assessment of anxiety symptoms. [73] However, how symptom levels in both these domains can be aggregated in a single outcome is unclear.

An alternate approach may be measures of non-specific psychological distress, which are effective screening scales for "serious mental illness" and are both widely used and relatively robust. [74] These measures are dimensional and can be used to assess changes in symptoms levels over time, but do not provide specific information on diagnostic categories. They may, however, add value when combined with another measure. For example, by measuring psychological distress in addition to depression, it should be possible to identify participants who do not meet the criteria for depression, but who are likely to have another disorder such as anxiety.

\section{Measurement of covariates}

Exposure to recent stressors has been repeatedly associated with new onsets of disorders and is usually included in each wave of a longitudinal study in the form of an assessment of major life events. [75] Personality trait neuroticism has also been consistently associated with increased risk and may reflect underlying susceptibility partly resulting from genetic makeup and childhood experience. $[20,76]$ It can be assessed with a brief questionnaire. [77]

A range of other individual and environmental covariates have been included in recent studies including family history, the extent of social networks,[78] physical activity,[79] and history of childhood sexual abuse. [80]

Effects of the physical and social environment can be considered by asking study participants to report on characteristics of their homes, social networks and neighborhood. [58] More objective environmental information can be gathered directly by researchers, or from secondary data. [81] Past analyses have often considered the impact of neighborhood-level socioeconomic disadvantage (for example mean household income). While interesting, this is a broad measure that reflects more the characteristics of the neighborhood population than structural features that are amenable to intervention. Examining the impact of other characteristics such as crime levels, neighborhood disorder and urban design has been positive for outcomes such as walking[82-84] and may be worth considering as a contributor to mental health. However, neighborhood factors such as these, and those available from the Census, tend to be highly collinear and need to be considered in constructs that are consistent with theories of neighborhood effects. One way to do this is using factor analysis to derive a parsimonious and uncorrelated set of factors that capture the key neighborhood socio-economic and socio-demographic measures of interest. $[85,86]$

\section{Analytical approaches}

Having dimensional information from multiple waves allows approaches to analysis that are not possible when examining diagnostic changes over a more limited followup. However, one issue that needs to be borne in mind when considering and communicating the complex findings that arise from repeated longitudinal data is total survey error. The potential for sampling error, coverage error, measurement error and non-response error to influence study findings is compounded in such research and any limitations arising from these need to be clearly communicated.

At its most simple, analyses of longitudinal datasets can examine the predictors of change in symptom scores for a particular disorder. Descriptive analyses could also explore how symptoms of both anxiety and depression vary over time.

Latent Class Analysis can be used to determine whether certain symptoms tend to cluster in subtypes within, or across, disorders[51], while latent growth models[87] and their extension; general growth mixture models [88] can be used to measure symptom trajectories. Longitudinal analysis could then stratify by these categories to examine whether the influence of covariates of interest varies by subtype.

Having data available for two covariates (for example symptoms of depression and physical activity) over several study waves, makes it possible to explore whether change in one of these variables, preceded change in the other. One way of doing this is with Dual Change Score Models, which distinguish true from error variance independently for the two variables of analysis, model the variables' systematic change, and simultaneously include competing hypotheses about lead-lag effects between the two variables. $[89,90]$ They can also estimate the systematic change patterns of both variables, each variable's autoproportional effect, and the coupling effect that each variable may exert on the changes of the other variables. [91]

Where environmental exposures are identified at a neighborhood level, examination of environmental effects will 
often require multilevel models. [92,93] These can be used to estimate the fixed effects of neighborhood-level predictors as well as within- and between-neighborhood variability in individual-level outcomes. When considering neighborhood effects, the smaller the spatial unit, the greater the power. [94] However, it is also important to ensure that these areas have coherence with neighborhood boundaries that are meaningful to those who live within them.

\section{Conclusion}

Many important, and in some respects quite basic, questions remain about the life course of depression and anxiety disorders and the determinants of their incidence, recurrence and prognosis. Much research to date has been based in a diagnostic paradigm that reflects clinical experience. A greater focus on symptoms and changes in symptom severity has the potential to allow innovative approaches that may greatly increase our understanding of these important issues. These include better characterising the heterogeneity of disorders by considering symptom subtypes and trajectories, and by examining the relationship over time between symptoms of different affective disorders. Considering these conditions as dimensional, heterogeneous, entities may then allow us to identify individual and environmental factors that impinge only on specific subtypes. It is also likely to advance our search for genetic determinants of these common disorders.

While we have focused in this paper on the extant literature from studies using comprehensive diagnostic instruments, these issues are just as relevant to research using brief instruments. Indeed, the cost and efficiency of such studies means they may be best placed to answer some of the questions confronting us. However, if we are to significantly further our understanding of these disorders, it is crucial that, regardless of the instruments used, future longitudinal research better addresses the issues of comorbidity and heterogeneity.

\section{Abbreviations}

CHDS: Christchurch Health and Development Study; CIDI: Composite International Diagnostic Interview; DSM: Diagnostic and Statistical Manual of Mental Disorders; ECA: Epidemiological Catchment Area; NCS: National Co-morbidity Study; NEMESIS: Netherlands Mental Health Survey and Incidence Study; PHQ: Patient Health Questionnaire; PTSD: Posttraumatic Stress Disorder; QIDS-SR: Quick Inventory of Depressive Symptomatology - Self Report; SCID: Structured Clinical Interview for DSM; WMH-CIDI: World Mental Health

\section{Competing interests}

The authors declare that they have no competing interests.

\section{Authors' contributions}

JB conceived of the paper and oversaw manuscript preparation. SG helped develop the ideas discussed in the paper and contributed to manuscript preparation. DV contributed to debate and manuscript preparation.

\section{References}

I. Demyttenaere K, Bruffaerts R, Posada-Villa J, Gasquet I, Kovess V, Lepine JP, Angermeyer MC, Bernert S, de Girolamo G, Morosini P, Polidori G, Kikkawa T, Kawakami N, Ono Y, Takeshima T, Uda H, Karam EG, Fayyad JA, Karam AN, Mneimneh ZN, Medina-Mora ME, Borges G, Lara C, de Graaf R, Ormel J, Gureje O, Shen Y, Huang Y, Zhang M, Alonso J, et al.: Prevalence, severity, and unmet need for treatment of mental disorders in the World Health Organization World Mental Health Surveys. JAMA 2004, 29 I:258I-2590.

2. Kessler RC, McGonagle KA, Zhao S, Nelson CB, Hughes M, Eshleman $\mathrm{S}$, Wittchen H, Kendler KS: Lifetime and I2-Month Prevelence of DSM-III-R Psychiatric Disorders in the United States: Results from the National Comorbidity Survey. Arch Gen Psychiatry 1994, 5 I:8-19.

3. Kessler RC, Demler O, Frank RG, Olfson M, Pincus HA, Walters EE, Wang P, Wells KB, Zaslavsky AM: Prevalence and treatment of mental disorders, 1990 to 2003. N Engl J Med 2005, 352:25I5-2523.

4. Spijker J, Bijl RV, de GR, Nolen WA: Care utilization and outcome of DSM-III-R major depression in the general population. Results from the Netherlands Mental Health Survey and Incidence Study (NEMESIS). Acta Psychiatr Scand 200I, 104:19-24.

5. Bijl RV, de GR, Hiripi E, Kessler RC, Kohn R, Offord DR, Ustun TB, Vicente B, Vollebergh WA, Walters EE, Wittchen HU: The prevalence of treated and untreated mental disorders in five countries. Health Aff (Millwood) 2003, 22:122-133.

6. Wilhelm K, Mitchell P, Slade T, Brownhill S, Andrews G: Prevalence and correlates of DSM-IV major depression in an Australian national survey. J Affect Disord 2003, 72:155-162.

7. Jenkins R, Lewis G, Bebbington P, Brugha T, Farrell M, Gill B, Meltzer $\mathrm{H}$ : The National Psychiatric Morbidity Surveys of Great Britain - initial findings from the household survey. Int Rev Psychiatry 2003, 15:29-42.

8. Kessler RC, Chiu WT, Demler O, Merikangas KR, Walters EE: Prevalence, severity, and comorbidity of I 2-month DSM-IV disorders in the National Comorbidity Survey Replication. Arch Gen Psychiatry 2005, 62:617-627.

9. Merikangas KR, Lieb R, Wittchen HU, Avenevoli S: Family and high-risk studies of social anxiety disorder. Acta Psychiatr Scand 2003, 108:28-37.

10. Cox BJ, McWilliams LA, Enns MW, Clara IP: Broad and specific personality dimensions associated with major depression in a nationally representative sample. Compr Psychiatry 2004, 45:246-253.

II. Schmitz N, Kugler J, Rollnik J: On the relation between neuroticism, self-esteem, and depression: results from the National Comorbidity Survey. Compr Psychiatry 2003, 44:169-176.

12. Kessler RC, Berglund P, Demler O, Jin R, Merikangas KR, Walters EE: Lifetime prevalence and age-of-onset distributions of DSMIV disorders in the National Comorbidity Survey Replication. Arch Gen Psychiatry 2005, 62:593-602.

13. Wittchen HU, Burke JD, Semler G, Pfister H, Von CM, Zaudig M: Recall and dating of psychiatric symptoms. Test-retest reliability of time-related symptom questions in a standardized psychiatric interview. Arch Gen Psychiatry 1989, 46(5):437-43.

14. Eaton WW, Anthony JC, Tepper S, Dryman A: Psychopathology and attrition in the epidemiologic catchment area surveys. Am J Epidemiol 1992, 135:105I-1059.

15. Regier DA, Narrow WE, Rae DS: The epidemiology of anxiety disorders: the Epidemiologic Catchment Area (ECA) experience. J Psychiatr Res 1990, 24:3-I4.

16. Eaton WW, Kramer M, Anthony JC, Dryman A, Shapiro S, Locke BZ: The incidence of specific DIS/DSM-III mental disorders: data from the NIMH Epidemiologic Catchment Area Program. Acta Psychiatr Scand 1989, 79:163-178. 
17. Chen L, Eaton WW, Gallo J], Nestadt G: Understanding the heterogeneity of depression through the triad of symptoms, course and risk factors: a longitudinal, population-based study. J Affect Disord 2000, 59: I-I I.

18. Bijl RV, Ravelli A, van ZG: Prevalence of psychiatric disorder in the general population: results of The Netherlands Mental Health Survey and Incidence Study (NEMESIS). Soc Psychiatry Psychiatr Epidemiol 1998, 33:587-595.

19. Spijker J, de GR, Bijl RV, Beekman AT, Ormel J, Nolen WA: Determinants of persistence of major depressive episodes in the general population. Results from the Netherlands Mental Health Survey and Incidence Study (NEMESIS). J Affect Disord 2004, 8 I:23 I-240.

20. De Graaf R, Bijl RV, Ravelli A, Smit F, Vollebergh WA: Predictors of first incidence of DSM-III-R psychiatric disorders in the general population: findings from the Netherlands Mental Health Survey and Incidence Study. Acta Psychiatr Scand 2002 1 06:303-13.

21. Wittchen H, Frohlich C, Behrendt S, Gunther A, Rehm J, Zimmermann $P$, Lieb R, Perkonnig A: Cannabis use and cannabis use disorders and their relationship to mental disorders: a I0-year prospective-longitudinal community study in adolescents. Drug Alcohol Depend 2007, 88:S60-70.

22. Bittner A, Goodwin RD, Wittchen HU, Beesdo K, Hofler M, Lieb R: What characteristics of primary anxiety disorders predict subsequent major depressive disorder? J Clin Psychiatry 2004 65:618-626.

23. Perkonigg A, Yonkers KA, Pfister H, Lieb R, Wittchen HU: Risk factors for premenstrual dysphoric disorder in a community sample of young women: the role of traumatic events and posttraumatic stress disorder. J Clin Psychiatry 2004, 65:1314-1322.

24. Perkonigg A, Pfister H, Stein MB, Hofler M, Lieb R, Maercker A, Wittchen HU: Longitudinal course of posttraumatic stress disorder and posttraumatic stress disorder symptoms in a community sample of adolescents and young adults. Am J Psychiatry 2005, 162:1320-1327.

25. Bronisch T, Schwender L, Hofler M, Wittchen HU, Lieb R: Mania, hypomania, and suicidality: findings from a prospective com munity study. Arch Suicide Res 2005, 9:267-278.

26. Henquet C, Krabbendam L, Spauwen J, Kaplan C, Lieb R, Wittchen $\mathrm{HU}$, van Os J: Prospective cohort study of cannabis use, predisposition for psychosis, and psychotic symptoms in young people. BM] 2005, 330: I I

27. Kessler RC, Merikangas KR, Berglund P, Eaton WW, Koretz DS, Walters EE: Mild Disorders Should Not Be Eliminated From the DSM-V. Arch Gen Psychiatry 2003, 60: I I 17-1 122.

28. Skapinakis P, Weich S, Lewis G, Singleton N, Araya R: Socio-economic position and common mental disorders. Longitudinal study in the general population in the UK. Br J Psychiatry 2006, I 89:109-II7.

29. Breslau N, Schultz LR, Johnson EO, Peterson EL, Davis GC: Smoking and the risk of suicidal behavior: a prospective study of a community sample. Arch Gen Psychiatry 2005, 62:328-334.

30. Patel V, Kirkwood BR, Pednekar S, Weiss H, Mabey D: Risk factors for common mental disorders in women. Population-based longitudinal study. $\mathrm{Br} J$ Psychiatry 2006, I 89:547-555.

31. Fergusson D, Horwood L: The Christchurch Health and Development Study: review of findings on child and adolescent mental health. Aust N Z J Psychiatry 2001, 35:287-296.

32. Fergusson DM, Horwood LJ, Ridder EM, Beautrais AL: Sexual orientation and mental health in a birth cohort of young adults. Psychol Med 2005, 35:971-98I

33. Cannon M, Caspi A, Moffitt TE, Harrington H, Taylor A, Murray RM, Poulton R: Evidence for early-childhood, pan-developmental impairment specific to schizophreniform disorder: results from a longitudinal birth cohort. Arch Gen Psychiatry 2002, 59:449-456.

34. Krueger RF: Personality traits in late adolescence predict mental disorders in early adulthood: a prospective-epidemiological study. J Pers 1999, 67:39-65.

35. Caspi A, Sugden K, Moffitt TE, Taylor A, Craig IW, Harrington H, McClay J, Mill J, Martin J, Braithwaite A, Poulton R: Influence of life stress on depression: moderation by a polymorphism in the 5-HTT gene. Science 2003, 301:386-389.
36. Copeland JR, Beekman AT, Dewey ME, Hooijer C, Jordan A, Lawlor BA, Lobo A, Magnusson H, Mann AH, Meller I, Prince MJ, Reischies F, Turrina C, deVries MW, Wilson KC: Depression in Europe. Geographical distribution among older people. Br J Psychiatry 1999 , I 74:3|2-32|

37. Kendler KS, Gardner CO, Prescott CA: Toward a comprehensive developmental model for major depression in men. Am J Psychiatry 2006, 163:115-124.

38. Kendler KS, Gardner MD, Prescott CA: Toward a Comprehensive Developmental Model for Major Depression in Women. Am J Psychiatry 2002, I 59: I | 33- I | 45

39. Eaton WW, Anthony IC, Gallo J, Cai G, Tien A, Romanoski A, Lyketsos C, Chen LS: Natural history of Diagnostic Interview Schedule/DSM-IV major depression. The Baltimore Epidemiologic Catchment Area follow-up. Arch Gen Psychiatry 1997, 54:993-999.

40. Copeland JR, Beekman AT, Dewey ME, Hooijer C, Jordan A, Lawlor BA, Lobo A, Magnusson H, Mann AH, Meller I, Prince MJ, Reischies F, Turrina C, deVries MW, Wilson KC: Depression in Europe. Geographical distribution among older people. Br J Psychiatry 1999, I 74:3|2-32|.

4I. Davey A, Halverson CF Jr, Zonderman AB, Costa PT Jr: Change in depressive symptoms in the Baltimore longitudinal study of aging. J Gerontol B Psychol Sci Soc Sci 2004, 59(6):P270-277.

42. Fiske A, Gatz M, Pedersen NL: Depressive symptoms and aging: the effects of illness and non-health-related events. J Geronto B Psychol Sci Soc Sci 2003, 58(6):P320-328.

43. Wittchen HU, Kessler RC, Pfister H, Lieb M: Why do people with anxiety disorders become depressed? A prospective-longitudinal community study. Acta Psychiatr Scand, Supplementum 2000, I 02(SUPPLEMENTUM NO 406): | 4-23.

44. Krueger RF: The structure of common mental disorders. Arch Gen Psychiatry 1999, 56(1 0):921-6.

45. Krueger RF, Caspi A, Moffitt TE, Silva PA: The Structure and Stability of Common Mental Disorders (DSM-III-R): A longtitudinal - Epidemiological Study. J Abnorm Psychol I998, 107:216-227

46. Ormel J, Oldehinkel AJ, Goldberg DP, Hodiamont PPG, Wilmink FW Bridges $\mathrm{K}$ : The structure of common psychiatric symptoms: how many dimensions of neurosis? Psychol Med 1995, 25:521-530.

47. Wittchen HU, Kessler RC, Pfister H, Lieb M: Why do people with anxiety disorders become depressed? A prospective-longitudinal community study. Acta Psychiatr Scand, Supplementum 2000, I 02(SUPPLEMENTUM NO 406): | 4-23.

48. Fergusson DM, Horwood LJ, Boden JM: Structure of internalising symptoms in early adulthood. $B r J$ Psychiatry 2006, I 89:540-546.

49. Beard JR, Dietrich UC, Brooks LO, Brooks RT, Heathcote K, Kelly B: Incidence and Outcomes of Mental Disorders in a Regional Population: The Northern Rivers Mental Health Study. Aust N ZJ Psychiatry 2006, 40:674-682.

50. Kendler KS, Eaves LJ, Walters EE, Neale MC, Heath AC, Kessler RC: The identification and validation of distinct depressive syndromes in a population-based sample of female twins. Arch Gen Psychiatry 1996, 53:391-399.

51. Sullivan PF, Kessler RC, Kendler KS: Latent class analysis of lifetime depressive symptoms in the national comorbidity survey. Am J Psychiatry 1998, I55: I398-I406.

52. Elliott MR, Gallo J, Ten Have TR, Bogner HR, Katz IR: Using a Bayesian latent growth curve model to identify trajectories of positive affect and negative events following myocardial infarction. Biostatistics 2005, 6: I 19-143.

53. McGue M, Christensen $K$ : The heritability of depression symptoms in elderly Danish twins: occasion-specific versus general effects. Behav Genet 2003, 33:83-93.

54. Rodriguez D, Moss HB, Udrain-McGovern J: Developmental heterogeneity in adolescent depressive symptoms: associations with smoking behavior. Psychosom Med 2005, 67:200-210.

55. Stoolmiller M, Kim HK, Capaldi DM: The course of depressive symptoms in men from early adolescence to young adulthood: identifying latent trajectories and early predictors. Abnorm Psychol 2005, I | 4:33 I-345.

56. Galea S, Ahern J, Nandi A, Tracy M, Beard J, Vlahov D: Urban neighborhood socioeconomic status and incidence of depression: Evidence from a population-based cohort study. Ann Epidemiol 2007, 17:17|-179. 
57. Yen I, Kaplan G: Poverty area residence and changes in depression and perceived health status: evidence from the Alameda County Study. Int J Epidemiol 1999, 28:90-94.

58. Latkin CA, Curry AD: Stressful neighborhoods and depression: a prospective study of the impact of neighborhood disorder. $J$ Health Soc Behav 2003, 44:34-44.

59. Caspi A, Moffitt T: Gene-environment interactions in psychiatry:joing forces with neuroscience. Nat Rev Neurosci 2006, 7:583-590

60. Manolio T, Bailey-Wilson J, Collins F: Genes, environment and the value of cohort studies. Nat Rev Genet 2006, 7:8I2-820.

61. Brugha TS, Bebbington PE, Jenkins R: A difference that matters: comparisons of structured and semi-structured psychiatric diagnostic interviews in the general population. Psychol Med 1999, 29:1013-1020.

62. Brugha TS, Bebbington PE, Jenkins R, Meltzer $H$, Taub NA, Janas $M$, Vernon J: Cross validation of a general population survey diagnostic interview: a comparison of CIS-R with SCAN ICD- I 0 diagnostic categories. Psychol Med 1999, 29:1029-1042.

63. Brugha TS, Jenkins R, Taub N, Meltzer H, Bebbington PE: A general population comparison of the Composite International Diagnostic Interview (CIDI) and the Schedules for Clinical Assessment in Neuropsychiatry (SCAN). Psychol Med 200I, 31: $1011-1013$

64. Kessler RC, Berglund P, Demler O, Jin R, Koretz D, Merikangas KR, Rush AJ, Walters EE, Wang PS, National Comorbidity Survey Replication: The epidemiology of major depressive disorder: results from the National Comorbidity Survey Replication (NCS-R). JAMA 2003, 289:3095-3105.

65. Kruijshaar ME, Hoeymans N, Bijl RV, Spijker J, Essink-Bot ML: Levels of disability in major depression: findings from the Netherlands Mental Health Survey and Incidence Study (NEMESIS). J Affect Disord 2003, 77:53-64.

66. Fergusson DM, Horwood LJ: Predictive validity of categorically and dimensionally scored measures of disruptive childhood behaviors. J Am Acad Child Adolesc Psychiatry 1995, 34:477-485.

67. Regeer EJ, Krabbendam L, de GR, ten HM, Nolen WA, van OJ: A prospective study of the transition rates of subthreshold (hypo)mania and depression in the general population. Psychol Med 2006, 36:619-627.

68. Brugha TS: The end of the beginning: a requiem for the categorization of mental disorder? Psychol Med 2002, 32: I |49- I I 54

69. Rush AJ, Trivedi MH, Ibrahim HM, Carmody TJ, Arnow B, Klein DN, Markowitz JC, Ninan PT, Kornstein S, Manber R, Thase ME, Kocsis JH, Keller MB: The I6-Item Quick Inventory of Depressive Symptomatology (QIDS), clinician rating (QIDS-C), and selfreport (QIDS-SR): a psychometric evaluation in patients with chronic major depression. [erratum appears in Biol Psychiatry. 2003 Sep 1;54(5):585]. Biol Psychiatry 2003, 54:573-583.

70. Kroenke K, Spitzer RL, Williams JB: The PHQ-9: validity of a brief depression severity measure. J Gen Intern Med 200I, I 6:606-6I 3.

7I. Lowe B, Spitzer RL, Grafe K, Kroenke K, Quenter A, Zipfel S, Bucholz C, Witte $S$, Herzog W: Comparative validity of three screening questionnaires for DSM-IV depressive disorders and physicians' diagnoses. I Affect Disord 2004, 78: | 3 |- | 40.

72. Haro JM, rbabzadeh-Bouchez S, Brugha TS, de GG, Guyer ME, Jin R, Lepine JP, Mazzi F, Reneses B, Vilagut G, Sampson NA, Kessler RC: Concordance of the Composite International Diagnostic Interview Version 3.0 (CIDI 3.0) with standardized clinical assessments in the WHO World Mental Health surveys. Int J Methods Psychiatr Res 2006, I 5:167-180.

73. Spielberger C, Gorusch R, Lushene R: State-Trait Anxiety Inventory Palo Alto: Consulting Psychologists Press; 1970.

74. Kessler RC, Barker PR, Colpe LJ, Epstein JF, Gfroerer JC, Hiripi E, Howes MJ, Normand S-LT, Manderscheid RW, Walters EE, Zaslavsky $A M$ : Screening for serious mental illness in the general population. Arch Gen Psychiatry 2003, 60: I84-189.

75. Kessler RC: The Effects of Stressful Life Events on Depression. Ann Rev Psychiatry 1997, 48:19|-2|4.

76. Kendler KS, Kuhn J, Prescott CA: The interrelationship of neuroticism, sex, and stressful life events in the prediction of episodes of major depression. Am / Psychiatry 2004, 16 1:631-636.

77. Sato T: The Eysenck Personality Questionnaire Brief Version: factor structure and reliability. J Psychol 2005, I 39:545-552.
78. Glass TA, de Leon CF, Bassuk SS, Berkman LF: Social engagement and depressive symptoms in late life: longitudinal findings. J Aging Health 2006, 1 8:604-628.

79. Strawbridge WJ, Deleger S, Roberts RE, Kaplan GA: Physical activity reduces the risk of subsequent depression for older adults. Am J Epidemiol 2002, I 56:328-334.

80. Kendler KS, Kuhn JW, Prescott CA: Childhood sexual abuse, stressful life events and risk for major depression in women. Psychol Med 2004, 34: |475-|482.

8I. Galea S, Ahern J, Nandi A, Tracy M, Beard J, Vlahov D: Urban neighborhood poverty and the incidence of depression in a population based cohort study. Ann Epidemiol 2007, I7: I7| - I79.

82. Giles-Corti B, Donovan RJ: Relative influences of individual, social environmental, and physical environmental correlates of walking. Am J Public Health 2003, 93: I583-I589.

83. Yen IH, Kaplan GA: Poverty area residence and changes in physical activity level: evidence from the Alameda County Study. Am J Public Health 1998, 88: I709-1712.

84. King WC, Belle SH, Brach JS, Simkin-Silverman LR, Soska T, Kriska AM: Objective measures of neighborhood environment and physical activity in older women. Am J Prev Med 2005, 28:46 I-469.

85. Beard J, Cerda M, Blaney S, Ahern J, Vlahov D, Galea S: Neighbor hood characteristics and change in symptoms of depression in older residents of New York City. Am J Public Health 2008 in press.

86. Matheson FI, Moineddin R, Dunn JR, Creatore MI, Gozdyra P, Glazier $\mathrm{RH}$ : Urban neighborhoods, chronic stress, gender and depression. Soc Sci Med 2006, 63:2604-26I6.

87. Muthén $B$ : Latent variable modeling with longitudinal and multilevel data. In Sociological methodology Edited by: Raftery A Boston, MA: Blackwell Publishers; 1997:453-480.

88. Muthén L: M. Mplus user's guide (version 2) Muthén \& Muthén; $200 \mathrm{I}$.

89. McArdle J, Hamagami F: Latent difference score structural models for linear dynamic analyses with incomplete longitudinal data. In Structural equation modeling: Present and future Edited by: Collins L, Sayer M. Washington, DC: American Psychological Association; 2001:139-175.

90. McArdle J], Hamgami F, Jones K, Jolesz F, Kikinis R, Spiro A, Albert MS: Structural modeling of dynamic changes in memory and brain structure using longitudinal data from the normative aging study. J Gerontol B Psychol Sci Soc Sci 2004, 59(6):P294-304.

91. Ghisletta P, Bickel JF, Lovden M: Does activity engagement protect against cognitive decline in old age? Methodological and analytical considerations. I Gerontol B-Psychol Sci Soc Sci 2006, 61:P253-26I.

92. Diez Roux A: The Examination of Neighborhood Effects on Health: Conceptual and Methodological Issues Related to the Presence of Multiple Levels of Organization. In Neighborhoods and Health Edited by: Berkman L. New York: Oxford University Press; 2003:45-64.

93. Diez Roux AV: Investigating neighborhood and area effects on health. Am J Public Health 2001, 91: 1783-1789.

94. Krieger N, Chen JT, Waterman PD, Soobader MJ, Subramanian SV, Carson R: Geocoding and monitoring of US socioeconomic inequalities in mortality and cancer incidence: does the choice of area-based measure and geographic level matter?: the Public Health Disparities Geocoding Project. Am J Epidemiol 2002, I 56:47| -482.

\section{Pre-publication history}

The pre-publication history for this paper can be accessed here:

\section{http://www.biomedcentral.com/1471-244X/8/83/pre} pub 